only, but sheets for birds are under active preparation and a few reptiles are also included. The entries are constantly being revised as the much needed information comes in from all parts of the world. The mammal and reptile sheets have been compiled by $\mathrm{Mr}$. Noel Simon, Information Officer of IUCN ; the bird ones are being prepared by Colonel Vincent as ICBP Liaison Officer at Morges. At Nairobi a system of symbols was worked out by which rare species can be categorised both by their degree of rarity and by the gravity of the threat to their continued existence. It is hoped, in the next issue of ORYX, to start reproducing the lists of rare species from the Red Data Book.

The Red Data Book, even in its present incomplete state, is an invaluable tool for all who are trying to save the world's wildlife. It has been produced with the aid of a large grant from the World Wildlife Fund, and at present is not available for general circulation, being confined to officers and members of the executive organs of IUCN and WWF, to members of the Survival Service Commission, and to a very limited number of private individuals who make substantial donations towards the cost.

The January meeting of the Commission at Morges was concerned mainly with the steps needed to conserve "three-star " forms, this being the highest category of urgency for dealing with rare species. A routine " action treatment" for all threats as soon as they are reported was worked out, and special attention given to the acute problem of Madagascar, in view of the most alarming reports that had been received of the rate at which the forest habitat of the island's rare mammals was disappearing.

\title{
Pesticides and Wild Life
}

THE Nature Conservancy has issued the following statement on 1 pesticides, defined as substances used to control any animal or plant regarded as a pest ; the term includes herbicides, fungicides, insecticides, and rodenticides used in agriculture, horticulture and food storage.

The Conservancy have always appreciated that chemical control of certain plant and animal species is often desirable in the interests of agriculture. There is evidence to show, however, that certain pesticides can present longterm ecological hazards to wild life. Most herbicides used to-day are relatively non-toxic to birds and mammals. Of the insecticides, the organophosphorous substances are relatively non-persistent, although some, which are highly toxic, have on occasion caused severe local mortality. At present, however, certain highly persistent organo-chlorine insecticides appear to provide the main hazard to wild life. Since limitations were agreed on aldrin, dieldrin, and heptachlor used as spring cereal seed dressings, these insecticides probably do not now cause much direct poisoning. On the other hand, there is evidence to suggest that if these substances were to be continually absorbed in small amounts in food they could have important effects on reproduction. The sub-lethal effects of the persistent chemicals on reproduction may well prove to be much more serious than their direct effects. Until more is known about these effects produced by ingestion through food chains the Conservancy will continue to press that their use should be greatly curtailed. 


\section{The Need}

(a) The justification for using pesticides in a given situation should always be assessed against any associated dangers, e.g. to wild life, and the measures necessary to guard against them should be part of the conditions of use.

(b) In any case where the use of a pesticide is known to involve a hazard to wild life, other methods of control should be preferred if they are effective and practicable.

\section{The Suitability}

(a) Pesticides should be as specific as possible in their effects.

(b) Where the use of more than one pesticide is effective and commercially practicable for a specific purpose the least hazardous and the least persistent should be used at the lowest concentrations necessary to control the pest concerned.

\section{Safety in use}

(a) Strict attention must be paid to the precautions issued with a pesticide and the manufacturers' instructions must be adhered to.

(b) Pesticides which demand safety precautions too exacting to be followed faithfully in practice should not be used.

(c) Pesticides should never be applied in weather conditions that prevent full control being exercised in their application.

(d) Aerial spraying should be used only when no other method of application is likely to be effective and commercially practicable. This applies particularly to the use of persistent compounds.

(e) Pesticide containers should be designed for easy emptying, rinsing, and disposal to minimize the dangers arising from pesticides remaining in them after use. They should either be returned to the manufacturers in accordance with instructions or effectively destroyed.

$(f)$ There should be restrictions on the sale to the public, e.g. for private garden use, of pesticides whose use could be dangerous.

(g) Because of the rapid progress in the production of new pesticides and in the knowledge of their modes of action, intending users should consult and follow the recommendations in the official advisory publications issued from time to time by the appropriate Government agencies.

\section{PESTICIDES AND GOLDEN EAGLES}

$\mathrm{T}$ HERE was an unprecedented drop in the number of pairs of golden eagles rearing young in the Western Highlands of Scotland between 1961-63 : 29 per cent as compared with 72 per cent during 1937-60, according to a report on Insecticides and Scottish Golden Eagles, by J. D. Lockie and D. A. Ratcliffe, of the Nature Conservancy, published in British Birds. The nesting failures have included breakage of eggs by the eagles themselves, and the inability of the females to lay eggs. Ten eggs from seven eyries were contaminated with dieldrin, gamma-BHC and DDE. All but one had traces of heptachlor epoxide, and circumstantial evidence strongly suggested that these chlorinated hydrocarbons were responsible for the decline. Apart from the heptachlor, the birds probably get the insecticides from the fat, flesh, and fleece of sheep carrion, the sheep having absorbed them from sheep dips. The authors conclude that the decline is attributable mainly to these residues of chlorinated hydrocarbons, particularly dieldrin, in the adult birds and their eggs. As at least two-thirds of the British breeding population of eagles lives in sheep country, and, if the chemicals continue to be used, is likely to be affected, the population decline may follow that of the peregrine. 